\title{
PEGylated nanoparticles for biological and pharmaceutical applications
}

\author{
Hidenori Otsuka $^{\mathrm{a}, 1}$, Yukio Nagasaki ${ }^{\mathrm{b}}$, Kazunori Kataoka ${ }^{\mathrm{c}, *}$ \\ ${ }^{a}$ Biomaterials Center, National Institute for Materials Science, 1-1 Namiki, Tsukuba, Ibaraki 305-0044, Japan \\ ${ }^{\mathrm{b}}$ Department of Materials Science, Tokyo University of Science, Noda, Chiba 278-8510, Japan \\ ${ }^{c}$ Department of Materials Science and Engineering, Graduate School of Engineering, The University of Tokyo, Hongo 7-3-1, \\ Tokyo 113-8656, Japan
}

Received 22 April 2002; accepted 16 September 2002

\begin{abstract}
The utility of polymeric micelles formed through the multimolecular assembly of block copolymer was comprehensively described as novel core-shell typed colloidal carriers for drug and gene targeting. Particularly, novel approaches for the formation of functionalized poly(ethylene glycol) (PEG) layers as hydrophilic outer shell were focused to attain receptormediated drug and gene delivery through PEG-conjugated ligands with a minimal non-specific interaction with other proteins. Surface organization of block copolymer micelles with cross-linking core was also described from a standpoint of the preparation of a new functional surface-coating with a unique macromolecular architecture. The micelle-attached surface and the thin hydrogel layer made by layered micelles exhibited nonfouling properties and worked as the reservoir for hydrophobic reagents. Furthermore, the potential utility of multimolecular assembly derived from heterobifunctional PEGs and block copolymers were explored to systematically modify the properties of metal and semiconductor nanostructures by controlling their structure and their surface properties, making them extremely attractive for use in biological and biomedical applications.
\end{abstract}

(C) 2002 Elsevier Science B.V. All rights reserved.

Keywords: Poly(ethylene glycol); Block copolymers; Biological and biomedical applications

\section{Contents}

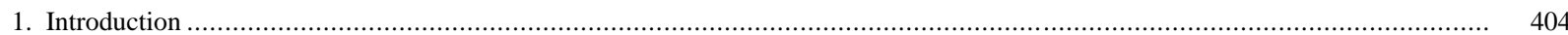

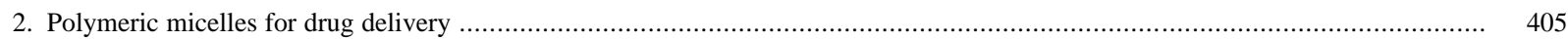

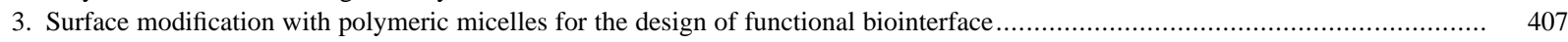

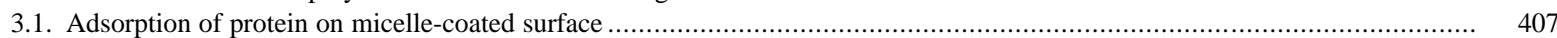

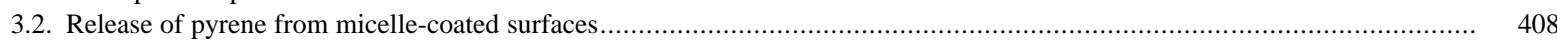

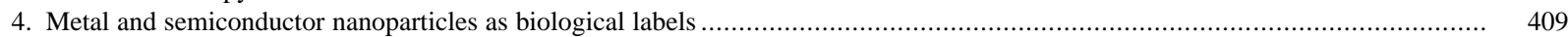

\footnotetext{
*Corresponding author. Tel.: + 81-3-5841-7138; fax: + 81-3-5841-7139.

E-mail address: kataoka@bmw.t.u-tokyo.ac.jp (K. Kataoka).

${ }^{1}$ Present address: Biomaterials Center, National Institute for Materials Science, 1-1 Namiki, Tsukuba, Ibaraki 305-0044, Japan.

0169-409X/02/\$ - see front matter C 2002 Elsevier Science B.V. All rights reserved.

doi:10.1016/S0169-409X(02)00226-0
}

(C) 2012. This manuscript version is made available under the Elsevier user license 
4.1. Metal nanoparticles .

4.1.1. Metal nanoparticles synthesized in amphiphilic block coplymer micelle

4.1.2. Gold nanoparicles synthesized by heterobifunctional PEG

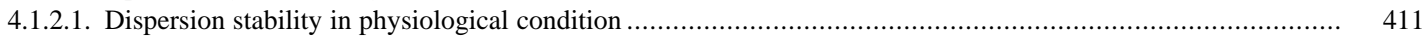

4.1.2.2. Quantitative and reversible lectin-induced association of gold nanoparticles.......................................

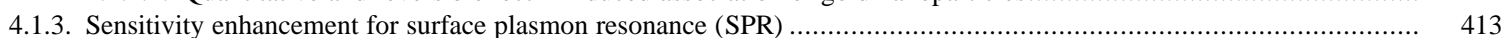

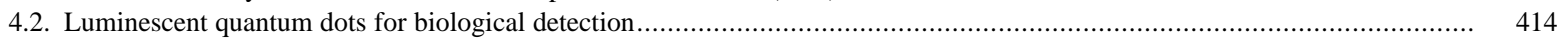

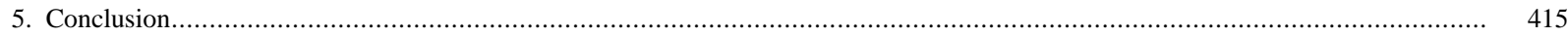

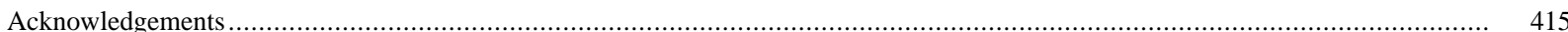

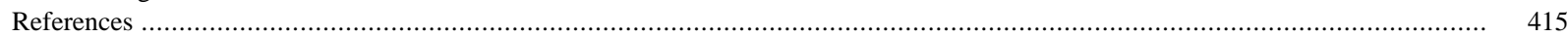

\section{Introduction}

Block copolymers with amphiphilic character, having a large solubility difference between hydrophilic and hydrophobic segments, have a tendency to self-assemble into micelles in a selective solvent [1-4]. In an aqueous solution, micelles with coreshell structure are formed through the segregation of insoluble hydrophobic blocks into the core, which is surrounded by a shell composed of hydrophilic blocks. This self-assembling property of amphiphilic block copolymers provides their high utility in the biomedical field as drug carriers, surface modifiers, and colloidal dispersants [5-8]. This review describes the recent progress in the field of block copolymer assembly in the solution and on the surface, focusing on the biological and biomedical application of poly(ethylene glycol) (PEG) based block copolymers. PEG chains as a hydrophilic polymers with a flexible nature can be selected as shell-forming segments, which assemble into dense palisades of tethered chains to achieve unique properies; The biocompatibility was guaranteed by the dense PEG shell, which endows the micelle with a stealth character in the blood compartment, achieving a long circulation [9]. PEG chains attached to a surface or forming the corona of a nanosphere exhibit rapid chain motion in an aqueous medium and have a large excluded volume. The steric repulsion resulting from a loss of conformational entropy of the bound PEG chains upon the approach of a foreign substance and the low interfacial free energy of PEG in water contribute to the extraordinary physiological properties of nanospheres covered with PEG [10-16]. PEG grafted to surfaces of biomedical devices also proved to increase their biocompatibility and to reduce thrombogenicity
[17-24]. Furthermore, surface organization of reactive micelles with cross-linking cores was described, allowing the surface to have extremely high nonfouling character and working as a reservoir for hydrophobic agents, as summarized in Fig. 1. Core segregation from aqueous milieu is the direct driving force for micellization and proceeds through a combination of intermolecular forces, including hydrophobic interaction [12,15,25-30], electrostatic interaction [31-34], metal complexation [35,36], and hydrogen bonding [37] of constituent block copopymers. A variety of drugs including genes and proteins, metals, and semiconductors with diverse characteristics can be incorporated into the coreforming segment of the block copolymer so that one can expect a sufficiently strong interaction with core-incoorporated molecules. In order to prepare the drug delivery system for site specificity, the outer shell of the polymeric micelle was buit in such a way that it was covered with fuctional groups, which react readily with potential pilot molecules or target-specific antibodies. These strategy to construct functionalized PEG layers was further applied to metal and semiconductor nanoparticles, which have recently attracted much interest in biological assay system due to their unique photochemical and photophysical properties [38-42]. These photonic properties depend on the particle size and composition, which can be varied with the method of preparation, including the use of Langmuir-Blodgett films [43,44], reverse micelles [45,46], vesicles [47], and various polymer networks [48-50], yet the resulting nanoparticles were not effective in preventing non-specific aggregation in aqueous medium unless their surface was modified with hydrophilic coatings including PEGylation. Accordingly, the surface organization of PEG on 


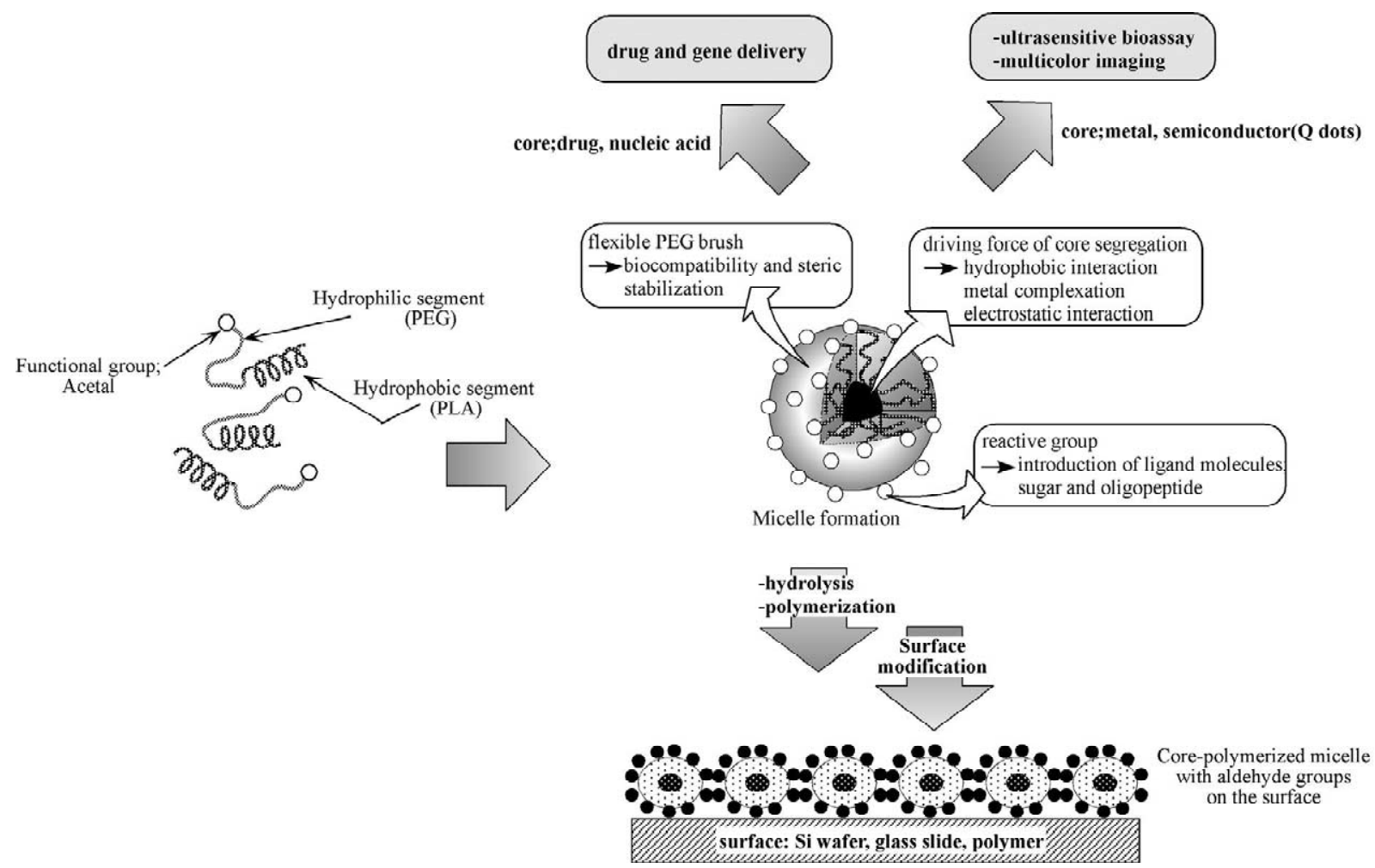

Fig. 1. Schematic representation of the application for the multimolecular assembly using heterobifunctional PEG and their block copolymer.

these nanoparticles may open the new opportunities to their use in the biological fields.

\section{Polymeric micelles for drug delivery}

Drug targeting for efficient accumulation in the body is often hampered by the rapid recognition of carrier system by the reticuloendothelial system (RES) and by the subsequent kidney and/or hepatic elimination. Moreover, for modulated drug delivery to solid tumors, which locate outside the blood compartment, the carrier is required to exhibit not just a sufficient half-life in the blood compartment, but also the capability of extravasation at the tumor site. Recent developments led to the design of drug carriers with prolonged circulation in the vascular system [9]. Cancer chemotherapy may cause severe side effects, leaving patients under extreme distress. To overcome this problem, an interest has been raised in the application of block copolymer micelles as a novel carrier systems for anticancer agents because of the high drug-loading capacity of the inner core as well as of the unique disposition characteristics in the body [9-12]. Compared to surfactant micelles, polymeric micelles are generally more stable, with a remarkably lowered crirical micelle concentration (CMC), and have a slower rate of dissociation, allowing retention of loaded drugs for a longer period of time and, eventually, achieving higher accumulation of a drug at the target site [9]. Polymeric micelles have a size of $30-50 \mathrm{~nm}$ in diameter, ranging closely to that of viruses, and apparently, this size range is favorable for extravasation to achieve so-called enhanced permeation retention effect (EPR effect) [51].

Special focus is focused here to polymeric micelles formed from heterobifunctional block copolymers. A challenge in the development of novel micellar carrier systems is to design targetable 
polymeric micelles in which pilot molecules are installed on their surface to achieve a specific-binding property to target cells. Of particular importance in this regard is the establishment of a novel and effective synthetic route for end-functionalized amphiphilic block copolymers with appreciable biocompatibility and biodegradability, allowing conjugation of the pilot molecules at the tethered end of the hydrophilic segment.

As reported previously, we have developed a facile and quantitative synthetic method for heterobifunctional PEG, which denotes PEG having different functional groups at the $\alpha$ - and $\omega$-ends [52-56]. This polymerization procedure is further applicable to the preparation of an end-functionalized block copolymer by extending a sec-end polymer segment from the $\omega$-end of the thus-prepared hetero-PEG, keeping the other functional group at the PEG chain end ( $\alpha$-end) to be available for further reaction. An introduction of an aldehyde group at the PEG end was achieved by the use of potassium 3,3-diethoxypropanolate (PDP) as an initiator for the polymerization of ethylene oxide (EO). The acetal group at the $\alpha$-end of resultant PEG can be easily converted into an aldehyde group by acid treatment. In this way, $\alpha$-acetal-poly(ethylene glycol)-block-poly(D,L-lactide) ( $\alpha$-acetalPEG-PLA) was synthesized by a one-pot anionic ring-opening polymerization of EO followed by $\mathrm{D}, \mathrm{L}-$ lactide (LA) initiated with PDP as an initiator at room temperature under argon (Scheme 1) [2124,57]. Because the PEG-PLA block copolymer has an amphiphilic character, it forms polymeric micelles in an aqueous milieu. A dialysis method was

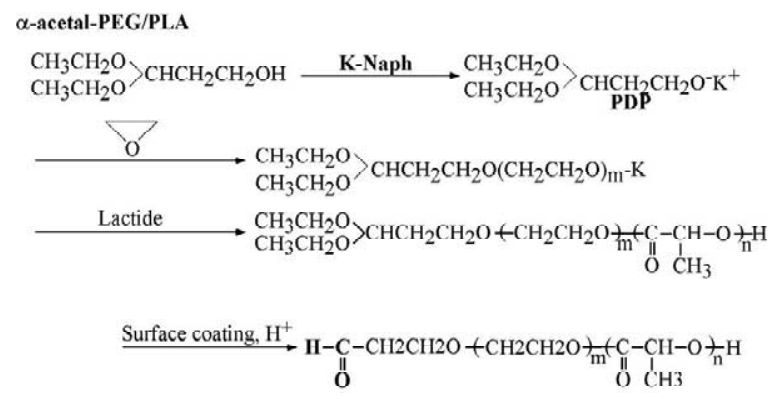

Scheme 1. Synthetic procedure of end-functionalized block copolymer $[\alpha$-acetal-poly(ethylene glycol)-poly(D,L-lactide) block copolymer]. employed to prepare the polymeric micelle, i.e. after the block copolymer was dissolved in a good solvent for both segment, such as dimethylacetamide (DMAc), the solution was dialyzed against water $[57,58]$. The size and shape of the polymeric micelles were estimated by dynamic light scattering (DLS/SLS), revealing the micelle to be $\sim 30 \mathrm{~nm}$ with a very low polydispersity. The conversion of the acetal end group into the aldehyde group was conducted after the micelle formation by adjusting the $\mathrm{pH}$ of the medium to $\mathrm{pH} 2$ with an addition of a small quantity of hydrochloric acid. From the ${ }^{1} \mathrm{H}$ NMR analysis, the conversion of acetal to aldehyde was estimated as up to $90 \%$.

The availability of the aldehyde groups positioned at the micelle's periphery for further modification was then confirmed through the reaction of the aldehyde groups with ligand molecules such as tyrosyl-glutamic acid (Tyr-Glu) as a model peptidyl ligand as well as saccharide moieties including glucose, galactose, and lactose [58,59].

The concept of polymeric micelle stabilization through the formation of a hydrophilic palisade surrounding a water-incompatible core can be extended to include the case of macromolecular association through electrostatic interaction. It was shown that a pair of block copolymers with an oppositely charged polyelectrolyte segment, poly(ethylene glycol)-block-poly(L-lysine) (PEG- $b$-PLL) and poly(ethylene glycol)-block-poly $(\alpha, \beta$-aspartic acid) (PEG- $b$-P(Asp)), spontaneously associates to form micelles with a core composed of polyion complex of poly(L-lysine) and $\operatorname{poly}(\alpha, \beta$-aspartic acid) segments. The polyion complex (PIC) micelles opened the way to incorporate charged macromolecules of synthetic and biological origins including proteins and nucleic acids into the micelles and have been developed as non-viral DNA delivery systems [32,60-62]. The strategy to coat the polyion complex core of a polycation and DNA with a hydrophilic segment of the cationic block copolymer was applied to prepare a variety of nanoassociates. These includes PEG- $b$-PLL $[31,61,62]$, poly(ethylene glycol)-block-poly(ethyleneimine) (PEG-b-PEI) [63], and poly(ethylene glycol)-blockpoly(dimethylaminoethyl methacrylate) (PEG- $b$ PAMA) [64], which were polymerized from corresponding monomers using PEG with the terminal 
functional group as a macroinitiator. Synthesis of these cationic block copolymers as well as physicochemical and biological properties of their micelles with DNA are reviewed in detail elsewhere $[5,65]$.

\section{Surface modification with polymeric micelles for the design of functional biointerface}

Providing polymeric micelles are able to be immobilized on the surface with maintaining their core-shell architecture, the aforementioned advantages of micelles in the solution, particularly nonfouling property, should be also expected on the surface. However, physical coagulation forces may not be stable enough to maintain the micelle structure in the process of surface fixation. A disruption of the micelle upon attachment to the surface is reported both experimentally and theoretically [6668]. Johner and Joanny [68] used scaling arguments to show the disruption of the micelles during their adsorption process. The disruption results in the formation of loops and trains on the surface, leading to the formation of a loosely packed layer structure. This discrepancy may be solved by the preparation of reactive and structurally stabilized micelles. Heterobifunctional block copolymers of PEG-PLA that possess reactive group at the PEG-end and polymerizable group at the PLA-end were successfully prepared. The polymerization of PLA-end after the micellization resulted in the formation of corepolymerized micelles with high stability in harsh environment [69].

Then, the core-stabilized reactive micelles were covalently linked to the surface, forming a single layer of micelle as well as multilayered highlyorganized micelle hydrogel [70-72]. Although the star polymers of PEG with micelle-like structure have been utilized for the surface modification to resist protein adsorption and to apply for the scaffold in tissue engineering by Merrill et al. and Griffith et al. [73,74], the polymeric micelle is expected to present more extended application for its easy preparation and unique structure. Since PEG density in the shell of the micelle is appreciably high, the surfaces treated with PEG-PLA micelles are eventually to have a dense layer of tethered PEG chain, which may provide an effective non- fouling property. Further, by incorporating hydrophobic drugs into the core of surface-immobilized micelles, one can create surfaces releasing drugs in a controlled manner.

\subsection{Adsorption of protein on micelle-coated surface}

The aminated glass slides and polypropyrene (PP) films were coated with monolayer and multilayers of micelles mediated by polyallylamine (PAlAm). The substrate was immersed in the micelle solution in HEPES ( $\mathrm{pH}$ 6.7) containing $\mathrm{NaCNBH}_{3}$ for $2 \mathrm{~h}$. After the light rinsing with Milli-Q water, the micelle-coated substrate was immersed into $0.6 \%(\mathrm{w} / \mathrm{v})$ PAlAm in HEPES $(\mathrm{pH}$ 6.7) containing $\mathrm{NaCNBH}_{3}$ for $2 \mathrm{~h}$. The above procedure was repeated until the desired number of coatings was obtained.

Surface covered with core-polymerized reactive micelle was evaluated by the protein adsorption measurements. The quantitative analysis of adsorbed proteins on the surface was carried out by the micro BCA method that determines small amount of protein in aqueous solution by the absorption of $\mathrm{Cu}^{+}$ chelated with bicinchoninic acid (BCA) [23,75]. Fig. 2 shows the equilibrated amount of BSA on the PP films after the exposure to $45 \mathrm{mg} / \mathrm{ml}$ of BSA solution for $60 \mathrm{~min}$. The micelle coating exhibited

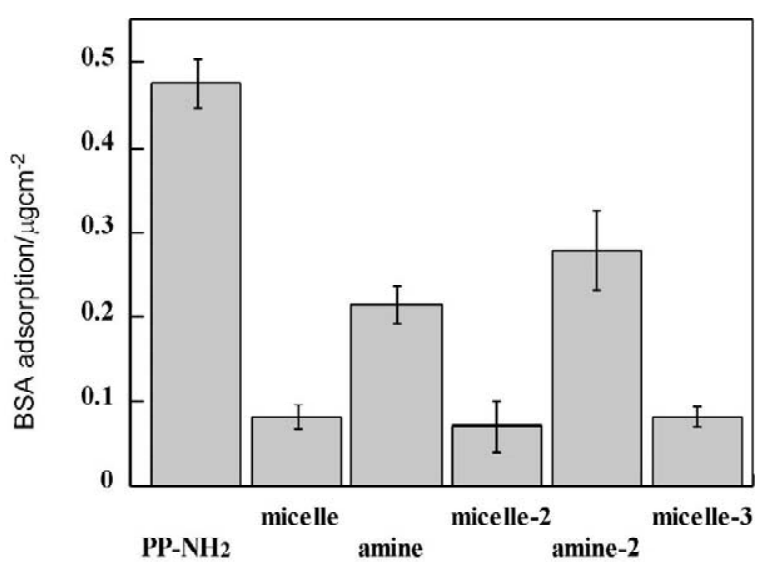

Fig. 2. Adsorption of BSA to aminated polypropylene surfaces modified with grafted PEG-aldehyde and reactive micelles. The numbers denote the numbers of layers of micelle and polyallylamine (PAlAm). 
significantly reduced amount of BSA compared with bare and plasma-treated PP plates (the surfaces aminated by plasma treatment necessarily for micelle coating through the reaction between the amine and aldehyde groups on the micelle). The non-fouling property against BSA was more significant than the surface grafted with PEG-aldehyde under the same condition as the micelle-coating. It should be noted that the protein adsorption reduced with increasing the number of micelle coating.

\subsection{Release of pyrene from micelle-coated surfaces}

The micellar gel has another unique property that is not typical of conventional hydrogels. The gel consists of micelles that have hydrophobic cores of $\sim 10 \mathrm{~nm}$ in size. The micelles on a surface are expected to hold drugs in the same manner as the ones in the solution, and to release them in a controlled manner. As a model drug, pyrene was incorporated into the micelle by mixing pyrene with the micellar solution, following the procedure by
Kwon et al. [76] The pyrene-incorporated micelles were coated on an aminated glass slide in the aforementioned manner. The sample was then exposed to an excess amount of Mili-Q water. By measuring the fluorescence at $\lambda_{\mathrm{ex}}=336 \mathrm{~nm}$, the release of pyrene from the micelle-coated surface was monitored. It is interesting to note that the initial amount of pyrene as well as the rate of release were dependent on the number of micelle coatings; as the number of coatings increased, the initial fluorescence was higher, and release-rate was slower. Repetitive loading and release of pyrene were also successfully accomplished with the micelle-gel layer as shown in Fig. 3. After the hexapoid coatings of pyrene-free micelle, the samples were exposed to the micelle solution containing pyrene for $12 \mathrm{~h}$ to transfer pyrene from solution to the gel phase. The loading and release of pyrene can be repeated reproducibly. The third cycle of the pyrene release carried out at $4{ }^{\circ} \mathrm{C}$ showed slower decline of fluorescence presumably due to the change in the mobility of the PLA segment with temperature, suggesting a variation in the release

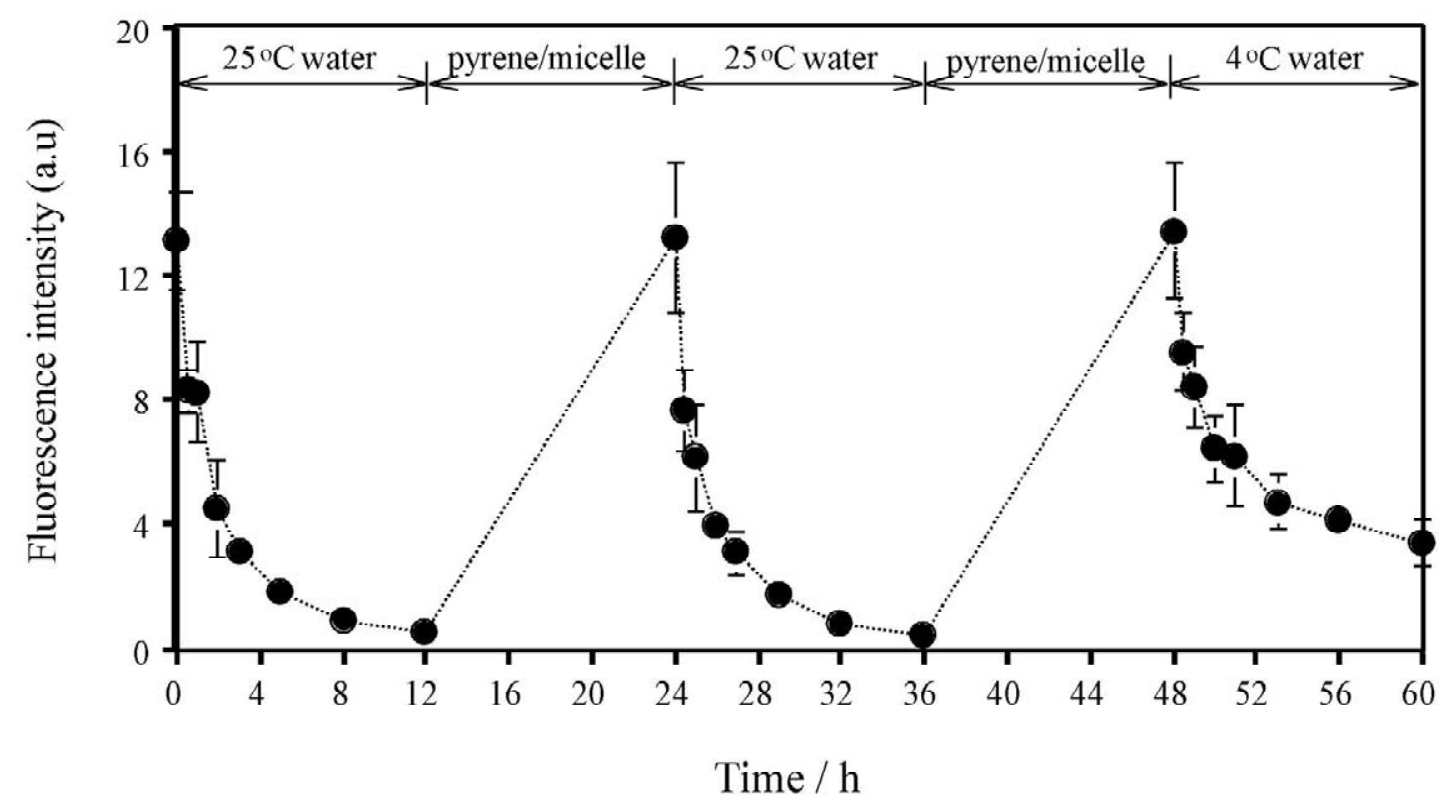

Fig. 3. Loading and releasing of pyrene from the aminated glass coated with hexapoid layer of micelle. 
rate obtained by the use of block copolymers with a hydrophobic segment that is different from PLA. These results indicate that the loading capacity and the release-rate of a drug can be controlled by the number of coatings.

\section{Metal and semiconductor nanoparticles as biological labels}

Metal and semiconductor nanoparticles are of considerable current interest because of their unique size-dependent properties [77-80]. By controlling the structure precisely at nanoscale dimensions, one can control and tailor properties of nanoparticles. In addition, one can modify the nanostructures to better suit for biological systems; for example, modifying their surface layer for enhanced aqueous solubility, biocompatibility, and biorecognition [81]. These ability to systematically modify the properties of nanoparticles by controlling their structure and their surface properties at a nanoscale level makes them extremely attractive candidates for use in biotechnological systems, from fundamental scientific studies to commercially viable technologies [82]. The use of exquisite recognition properties of biomolecules in organizing non-biological inorganic objects into functional materials becomes an important frontier in materials science. Recent research by several groups has linked colloidal nanoparticles to biomolecules such as sugars [83-86], peptides [87], proteins [88-90], and DNA [91-93]. These nanoparticle bioconjugates are being used for assembling new materials [94,95], for developing homo- and heterogeneous bioassays [96-98], particularly, multicolor fluorescent labels for ultrasensitive and high-throughput detection and imaging [88-92]. Many advantages are expected by replacing conventional molecular tags, such as fluorescent chromophores, with nanoparticles. These include higher quantum efficiencies, greater scattering or absorbance cross sections, optical activity over more biocompatible wavelengths, and significantly increased chemical or photochemical stability. The availability of these new nanoparticles will greatly facilitate in situ probes and sensor methods.

\subsection{Metal nanoparticles}

The use of gold colloid in biological applications began in 1971, when Faulf and Taylor invented the immunogold staining procedure. Since that time, the labeling of targeting molecules, especially proteins, with gold nanoparticles has revolutionized the visualization of cellular or tissue components by electron microscopy [99]. The optical and electron beam contrast qualities of gold colloid have provided excellent detection qualities for imaging technologies in electron microscopy. Although metal and inorganic nanoparticles can be prepared from various materials by several methods [100-104], the coupling and functionalization with biological components has only been carried out with a limited number of chemical methods.

To apply gold colloids in newly developed biomedical assay systems, a simple and facile means of anchoring different ligand biomolecules onto particle surfaces are strongly required as well as the stability in the physiological condition should be improved. Particularly, color changes induced by the association of nanometer-sized gold particles provide a basis of a simple yet highly selective method for detecting specific biological reactions between acnchored ligand molecules and receptor molecules in the milieu. Mirkin and co-workers have shown that gold colloidal particles modified with oligonucleotides form large assemblies through the hybridization with complementary oligonucleotide strands, providing a new method for colorimetric detection of targeted DNA sequences [9194,96,98]. With decreasing gold colloidal particle size, however, colloidal stability decreases significantly due to increased particle surface energy. Such gold nanoparticles aggregate in high ionic strength milieu as well as adsorb biomolecules such as proteins and DNA nonspecifically, resulting in reduced sensitivity and selectivity when used as colloidal sensor systems in biological fluids.

\subsubsection{Metal nanoparticles synthesized in amphiphilic block coplymer micelle}

Several methods have attempted to synthesize and stabilize nano-scale gold particles in aqueous milieu. Most of them have utilized surfactant and/ 
or polymer stabilizers, yet were not effective in preventing aggregation of nanoparticles particularly under physiological conditions (concentrated salt medium) [105].

Block copolymer micelles could successfully be used as nanoreactors for noble metal colloid formation; in such micelles, chemical and physical reactions can be confined to the fluid micellar cores, the size of which are confirmed as a nanometer scale. For the amphiphilic block copolymer in the non-polar selective solvent, the unpolar blocks form the corona, which provides solubilization and stabilization, while the polar or hydrophilic and functionalized blocks form the core, which is able to dissolve metal compounds due to coordination, followed by the nucleation and growth of metal particles upon reduction. The important step involves the solubilization of inorganic compounds into the micellar core. As a guideline for optimum precursor materials and micellar core blocks, one can use Pearsons hard/soft acid/base (HSAB) concept [106], which has been generalized to include metals and semiconductors [107]. The general strategy is to start from weakly coordinated metals, e.g. $\mathrm{Pd}(\mathrm{OAc})_{2}$ or $\mathrm{Pd}\left(\mathrm{ClO}_{4}\right)_{2}$ which are complexes of a soft acid (the transition metal ions) and a hard base (acetates, perchlorates, etc.). The formation of a more stable complex of a soft acid with a softer base, e.g. polyvinylpyridine, to assemble the micellar core, is the driving force for solubilizatikon. The polymer complex should not be too stable since over-stabilization could prevent the formation of the desired colloid in the subsequent chemical reaction. Chemical reactions typically involve reduction process to obtain noble metal colloids or the preparation of sulfides or oxides. Using polystyrene-poly4vinylpyridine (PS-b-P4VP) as the constituting amphiphilic block copolymer, Sidorov et al. prepared mono- and bimetallic colloids with size controlled by varying such parameters as species of metal salt, type of reducing agent, and block copolymer composition. However, the most study using amphiphilic block copolymers were successfully employed only in nonpolar organic solvents, because appropriate polymers to show both the ability to form micelles in water and to bind metals in the core are not available. Use of water as reaction medium becomes possible when double-hydrophilic block copolymer is adopted, where both blocks are soluble in water, but only one block is able to coordinate with metal ions. The example of such an application was reported for the interaction of PEGblock-PEI with $\mathrm{AuCl}_{3}, \mathrm{PdCl}_{2}, \mathrm{H}_{2} \mathrm{PtCl}_{6}, \mathrm{Na}_{2} \mathrm{PtCl}_{6}$, $\mathrm{K}_{2} \mathrm{PtCl}_{6}$, and $\mathrm{Na}_{2} \mathrm{PdCl}_{4}$ [108]. Addition of the gold salt to a PEG- $b$-PEI solution resulted in the formation of polydisperse micelles, and PEG- $b$-PEI induced reduction of the gold salt to form gold nanoparticles. Neither PEG nor PEI itself showed this behavior of auto-reduction. Analytical ultracentrifugation confirmed that $75-80 \%$ of the gold was formed inside the micelle, suggesting particle formation arround the PEI chains [108,109]. Micelle formation upon salt addition to a PEG- $b$-PEI solution was also observed for $\mathrm{PdCl}_{2}$ and $\mathrm{K}_{2} \mathrm{PtCl}_{4}$ with polydisperse, large, and unstable properties, but no self-reduction occurred in these cases. It was further found for PEG- $b$-PEI that branched copolymers with muliple PEG blocks attached to PEI are better stabilizers for metal nanoparticles as compared to the diblock system. Light scattering and transmission electron microscopy (TEM) revealed the existence of large micellar aggregates for the diblock system. If stable micelles were formed with the metal salts $\left(\mathrm{H}_{2} \mathrm{PtCl}_{6}, \mathrm{Na}_{2} \mathrm{PtCl}_{6}, \mathrm{Na}_{2} \mathrm{PdCl}_{4}\right)$, efficient control of the nanoparticle growth and stabilization was possible although the equilibration of the micelle architecture could be a slow process taking up to weeks [110]. Besides the identified parameter, such as polymer/metal ratio and type of reducing agent on the metal nanoparticle size and shape, complex ion geometry and also the $\mathrm{pH}$ of the solution were found to be of importance.

\subsubsection{Gold nanoparicles synthesized by heterobifunctional PEG}

Recently, Wuelfing et al. reported that surface PEGylation of gold particles by $\mathrm{CH}_{3} \mathrm{O}-\mathrm{PEG}-\mathrm{SH}$ significantly improved their dispersion stability in aqueous milieu due to steric repulsion effects of tethered PEG strands [111]. Yet, the $\mathrm{CH}_{3} \mathrm{O}-$ PEGylated nanoparticles possess no reactive groups to further immobilize ligand molecules. Thus, a system possessing both sufficient colloidal stability and biofunctionality is strongly desired [112,113] to construct quantitative bioassays using gold nanoparticles. Recently, we have reported a facile 
route to functionalize PEGylated gold nanoparticles, having a potential utility for colloidal sensor systems [114], by the use of newly-designed heterobifunctional PEG derivatives.

Our strategy to synthesize various types of heterobifunctional PEGs is based on the ring-opening polymerization of ethylene oxide using a metal alkoxide initiator with a protected functional group [52-56]. Synthesis of heterobifunctional PEG containing both mercapto and acetal terminal groups $(\alpha$-acetal- $\omega$-mercapto-PEG, acetal-PEG-SH) was previously reported as shown in Scheme $2 \mathrm{a}$. The acetal moiety can readily be transformed into a reactive aldehyde group by simple treatment with dilute acid. An aldehyde-functionalized PEGylation of gold nanoparticles using this acetal-PEG-SH $\left(M_{\mathrm{n}}=3090\right)$ was successfully achieved, obtaining gold nanoparticles with high dispersion stability, particularly in physiological milieu, and appreciable aldehyde reactivity to immobilize ligand molecules on the PEG coronas which additionally impart sensitivity and selectivity due to their non-fouling properties. As a model ligand, lactose was successfully introduced in the distal end of PEG chain to induce lectin-mediated quantitative and reversible association of gold nanoparticles under physiologically relevant conditions producing a concomitant color change (red $\rightarrow$ purple $\rightarrow$ red) as described in Scheme 3.

\subsubsection{Dispersion stability in physiological con- dition}

Gold nanoparticles were prepared by reduction of metal salt $\left(\mathrm{HAuCl}_{4}\right)$ with $\mathrm{NaBH}_{4}$ in the presence of acetal-PEG-SH. The formation of gold nanoparticles, an average diameter of $8.9 \mathrm{~nm}$ as measured by TEM, was confirmed by the UV-visible spectrum of an absorption band near $\lambda=520 \mathrm{~nm}$, assigned to a gold nanoparticle plasmon band.

Acetal-PEG-SH coated gold nanoparticles were appreciably stable in buffers of elevated salt concentrations $(\boldsymbol{O}, \boldsymbol{\Delta})$ and also in serum-containing medium $(\bigcirc)$, while gold nanoparticles physically stabilized through the adsorption of acetal-PEG-OH

(a) $\alpha$-acetal-PEG-SH

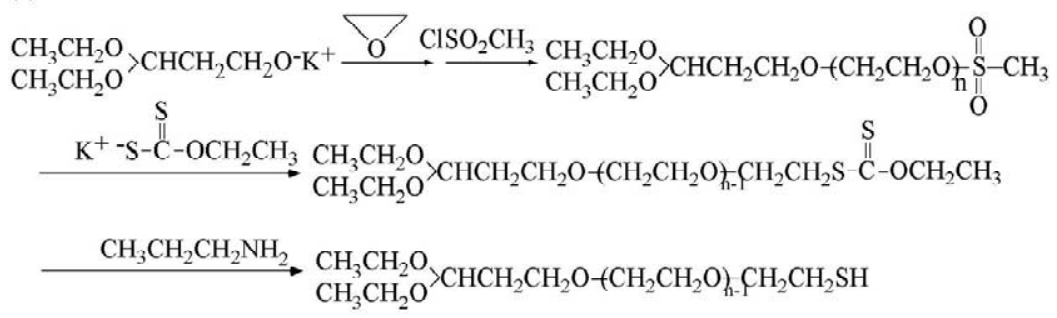

(b) PEG-b-PAMA

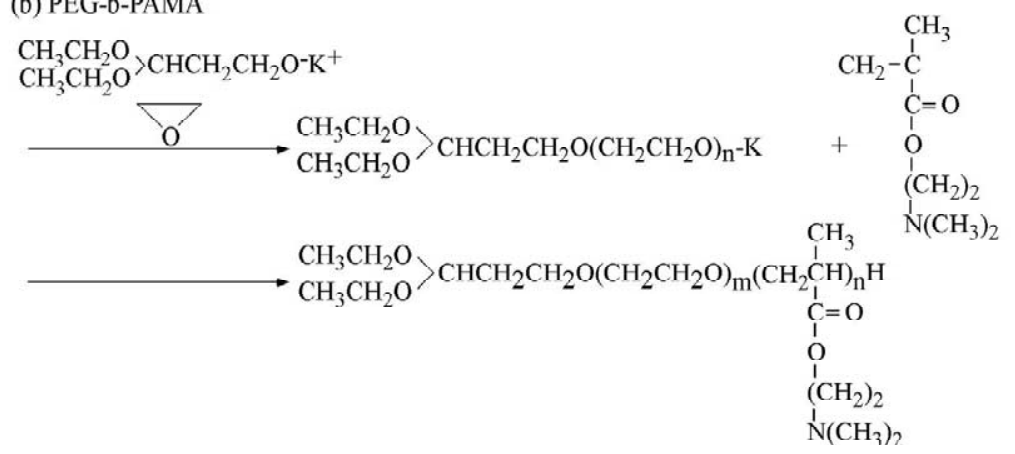

Scheme 2. Synthetic procedure of $\alpha$-acetal- $\omega$-mercapto-poly(ethylene glycol) (a) and cationic block copolymer [poly(ethylene glycol)-blockpoly(dimethylaminoethyl methacrylate)] (b). 


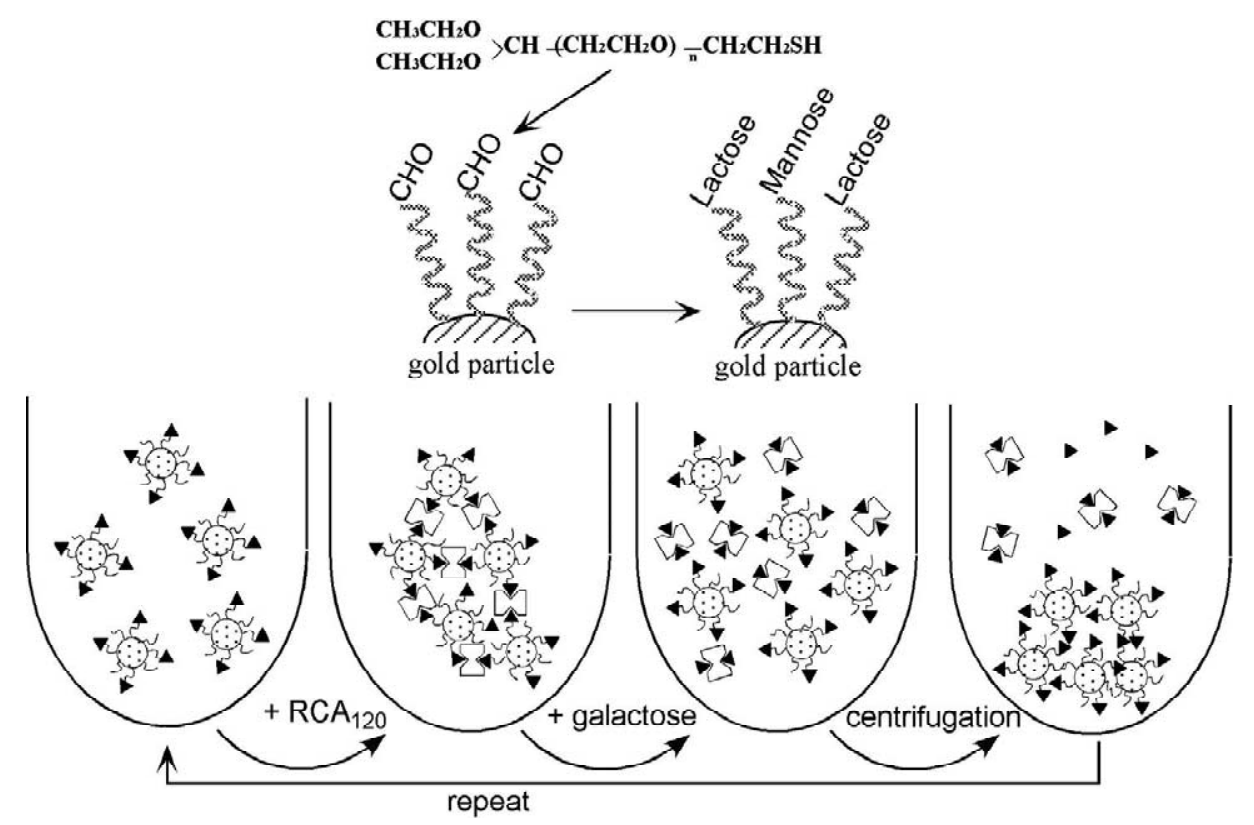

Scheme 3. Schematic representation of the reversible aggregation-dispersion behavior of Lac-PEGylated gold nanoparticles by sequential addition of $\mathrm{RCA}_{120}$ lectin and galactose with actual concomitant change in color from pinkish red $\rightarrow$ purple $\rightarrow$ pinkish red.

$\left(M_{\mathrm{n}}=3000\right)(\boldsymbol{\square}, \boldsymbol{\nabla})$ aggregated immediately even in $0.03 \mathrm{M}$ PBS (Fig. 4). Highly enhanced stabilization as well as reduced nonspecific interactions with biological components including cells and proteins of gold nanoparticles bearing acetal-PEG-SH allows this system to be developed for diagnostics in blood serum-containing samples.

\subsubsection{Quantitative and reversible lectin-induced association of gold nanoparticles}

The PEG acetal terminal group was converted to aldehyde by gentle acid treatment, followed by the reaction with sugar derivatives having $p$-aminophenyl moieties at the $\mathrm{C}-1$ position ( $p$-aminophenyl- $\beta$-D-lactopyranoside: Lac) in the presence of $\left(\mathrm{CH}_{3}\right)_{2} \mathrm{NHBH}_{3}$. Reaction of these Lac-derivatized gold nanoparticles with bivalent galactose-binding lectin (recinus communis agglutinin, $\mathrm{RCA}_{120}$ ) $[115,116]$ was followed as a function of time through optical changes in the surface plasmon band in the UV-Vis spectrum. These solutions were initially a pinkish-red color due to the well-dispersed nature of the particles (Scheme 3). After introduction of the $\mathrm{RCA}_{120}$ lectin in $0.15 \mathrm{M}$ PBS,

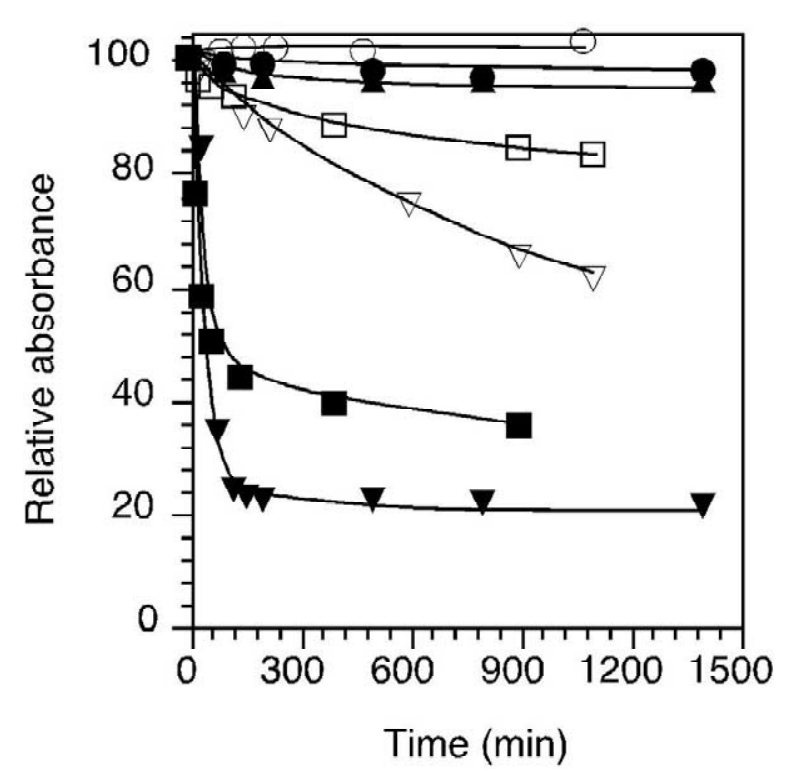

Fig. 4. Dispersion stability of gold nanoparticles with time in various environments. Acetal-PEG-SH protected gold nanoparticles in $0.15 \mathrm{M}$ PBS $(\bullet), 0.3 \mathrm{M}$ PBS $(\boldsymbol{\Delta})$, and $0.15 \mathrm{M}$ PBS with $2 \%$-serum $(\mathrm{O})$; acetal-PEG-OH adsorbed gold nanoparticles in 0.03 M PBS ( $\mathbf{\square}), 0.15$ M PBS $(\boldsymbol{\nabla}), 0.03$ M PBS with $2 \%$-serum $(\square)$, and 0.15 M PBS with $2 \%$-serum $(\nabla)$. 
the color gradually changes from red to purple (Scheme 3). In line with this directly observable change in appearance, significant differences in the optical spectra over time were observed, specifically a broadening and red shift in the particle surface plasmon resonance from $523 \mathrm{~nm}$ to longer wavelength [117] (Fig. 5). This is attributed to distancedependent changes in the optical properties of threedimensionally aggregated gold nanoparticles crosslinked by $\mathrm{RCA}_{120}$ lectin which recognizes lactose residues on the PEGylated gold surface. The lectinparticle system were well-ordered and three-dimensionally linked, as deduced from TEM and SAXS analysis. Images of two-dimensional, single layer aggregates revealed close-packed assemblies of the colloids with uniform particle separations of about $20 \mathrm{~nm}$, which corresponds to the length of the combination of lectin and PEG linker. The aggregation by the $\mathrm{RCA}_{120}$ lectin was reversible, recovering the original dispersed phase and color by addition of excess galactose. Notably, the degree of aggregation was proportional to lectin concentration, allow-

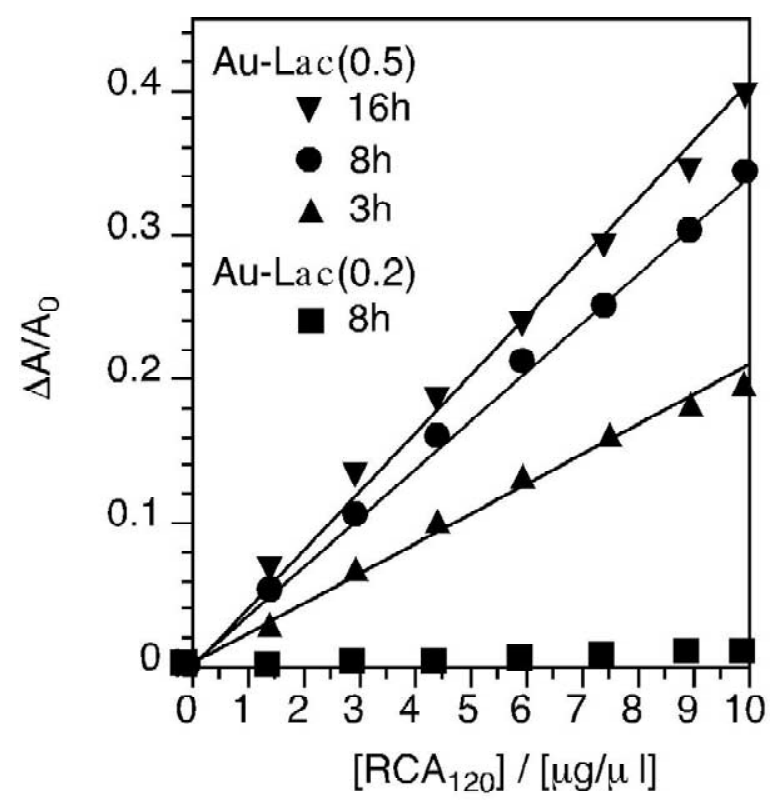

Fig. 5. Change in the surface plasmon band intensity $\left(\Delta A\left(=A_{0}-\right.\right.$ A) $/ A_{0}$ ) with $\mathrm{RCA}_{120}$ concentration $\left(\left[\mathrm{RCA}_{120}\right]\right)$ for nanoparticle $\operatorname{Au}-\operatorname{Lac}(0.5)(\boldsymbol{\Lambda}, \boldsymbol{Q}, \boldsymbol{\nabla})$ and $\mathrm{Au}-\operatorname{Lac}(0.2)(\mathbf{\square})$ at different times after onset of the aggregation reaction. $A_{0}$ is the surface plasmon band intensity in the absence of $\mathrm{RCA}_{120}$. ing the system to be utilized to quantitate lectin concentration with nearly the same sensitivity as enzyme-linked immunosorbent assay (ELISA) $(\cong 1$ $\mu \mathrm{g} / \mathrm{ml}(1 \mathrm{ppm}))$. This simple yet highly effective derivatization of gold nanoparticles with heterobifunctional PEG provides a convenient method to construct practical colloidal sensor systems currently applied in bioassays and biorecognition.

As an another interesting method to prepare gold nanoparticles with narrow size distribution, we have developed to use the PEG based cationic block copolymer, PEG- $b$-PAMA as a stabilyzer for gold nanoparticle preparation. Recent advances in our study showed that the metal-ligand coordination bond is able to be utilized as a driving force to form the core of the block copolymer micelles $[35,36]$. PEG- $b-\mathrm{P}(\mathrm{Asp})$ and cisplatin (cis-dichlorodiamineplatinum (II):CDDP) form micelles with the core of the polymer-metal complex through ligand exchange from chloride to carboxyl group of the poly(aspartic acid) segment. The similar concept of these micelle stabilization can be adopted to prepare and stabilize the gold nanoparticles particularly in physiological condition. The copolymerization of PEG- $b$-PAMA was achieved by the sequential anionic polymerization of ethyleneoxide and dimethylaminoethyl methacrylate (AMA). PDP was also employed as an initiator to introduce an acetal group at the end of the PEG segment of the block copolymer (Scheme 2b). Addition of the gold salt to a PEO- $b$-PAMA solution induced reduction of the gold salt to form extremely monodisperse gold nanoparticles without reductive agents. Further functionalization with biotin molecules at the PEG chain-end demonstrated extended aggregation of biotinylated gold nanoparticles through biotinavidin interaction.

\subsubsection{Sensitivity enhancement for surface plasmon resonance (SPR)}

Gold nanoparticles can also be applied to enhance detection limits in SPR-based real-time biospecific interaction analysis [118,119]. The dynamic enhancement of SPR biosensing with colloidal gold was initially observed in a sandwich immunoassay in which gold nanoparticles were coupled to a secondary antibody. This system was used to detect a primary antibody bound through specific immuno- 
sorption to the antigen immobilized on the gold sensor surface. Our recent study demonstrated that an appreciable enhancement in sensitivity was obtained to detect the avidin immobilized on the SPR sensor surface through biotin-avidin interaction using $\alpha$-biotynylated-PEG functionalized gold nanoparticles. The immunosorptive binding of the colloidal gold to the sensor surface led to a large shift in plasmon angle, a broadened plasmon resonance, and an increase in minimum reflectance, thereby allowing picomolar detection of antigen [118]. Similarly, an improvement in sensitivity by about 1000-fold was obtained in nucleic acid hybridization analysis, when a colloidal gold/oligonucleotide conjugate was used as a probe [119]. These results suggest that the detection limit of SPR [120] now begins to approach that of traditional fluorescence-based DNA hybridization detection system.

\subsection{Luminescent quantum dots for biological detection}

A unique property of semiconductor nanoparticles, known as quantum dots (QD) and metal nanoshell, is that they absorb and scatter light of the near infrared, a spectrum region where tissue is essentially transparent. These nanoparticles are often composed of atoms from II-VI or III-V elements in the periodic table. QDs are highly light-absorbable and luminescent with absorbance onset and emission maximum shift to higher energy with decreasing particle size due to quantum confinement effects [88]. These nanoparticles are in the size range of 2-8 $\mathrm{nm}$ in diameter. Unlike molecular fluorophores, which typically have very narrow exitation spectra, semiconductor QDs absorb light over a very broad spectral range. This makes it possible to optically excite a broad spectrum of QD colors using a single excitation laser wavelength, which enables one to simultaneously probe several markers. Thus, bioconjugated QDs have been used in DNA hybridization [91-94], immunoassay [89], receptor-mediated endocytosis [89], and time-gated fluorescence imaging of tissue sections [121]. QDs are also emerging as a new class of fluorescent labels for in vivo cellular imaging. An important advantage is that the extremely high photostability of QDs allows real-time monitoring or tracking of intracellular prosesses over long periods of time. Another advantage is the ability to use multicolor nanoparticles to simultaneously image multiple targets inside living cells or on the cell surface.

A typical QDs in these applications, CdS, have been synthesized via arrested precipitation from simple inorganic ions using polyphosphate and low molecular weight thiols as stabilizers [122,123], from dimethylcadmium in trioctyl phosphine using trioctyl phosphine oxide as a stbilizer, and from cadmium 2-ethylhexanoate in dimethyl sulfoxide (DMSO) using ethylhexanoate as a stabilizer. However, these QDs are practically synthesized at high temperature $\left(\sim 300^{\circ} \mathrm{C}\right)$ and the following bioconjugation was applied using several method; use of a bifunctional ligand such as mercaptoacetic acid for linking QDs to biomolecules [89], trioctylphosphine oxide (TOPO)-capped QDs bound to a modified acrylic acid polymer by hydrophobic forces, and QD solubilization and bioconjugation using a mercaptosilane compound [88]. All of these require high temperture and many processes for both synthesis and bioconjugation, further resulting QDs seem to be lack of stability and selectivity in physiological condition. In contrast, as well as the case for synthesis of gold nanoparticles, the PEG- $b$ PAMA solution containing the $\mathrm{Cd}$ (II) salt and $\mathrm{Na}_{2} \mathrm{~S}$, respectively, were simultaneously introduced to form $\mathrm{CdS}$ nanoparticles stabilized by PEG- $b$ PAMA at room temperature in aqueous solution. These nanoparticles showed not only the stability in concentrated salt solution but also biorecognition properties, demonstrating the high utility in the biomedical applications, particularly, high-throughput detection and imaging.

Interestingly, CdS/dendrimer nanocomposite was synthesized by the arrested precipitation of $\mathrm{CdS}$ in the presence of Starburst (PAMAM:poly(aminoamine)) dendrimers as stabilizers [124]. Recently, amino-derivatized polysaccharides (aminodextran or Amdex) were employed as a stabilizer for the preparation of stable aqueous dispersions consisting of CdS nanoparticles, and the resultant Amdex$\mathrm{CdS}$ nanoparticle complexes could be activated and conjugated with an antibody [125]. Due to the fact that the $\mathrm{CdS} /$ polymer nanocomposite underwent further aggregation in solution to produce mi- 
crometer-scale composite flocs, individual CdS nanparticles cannot be isolated in these CdS/polymer nanocomposites, resulting in the loss of photocmemical activity.

\section{Conclusion}

Recently, the tremendous progress has been attained in the characterization and application of nanostructured materials using block copolymers. Nanostructure fabrication from block copolymers involves polymer design, synthesis, self-assembly, and derivatization. Block copolymers self-assembled into micelle afford a powerful means of manipulating the characteristics of surfaces and interfaces, and therefore, are expected to have novel applications. In this review, nanoparticle fabrication using heterobifunctinal poly(ethylene glycol) (PEG) and their block copolymer is explored to construct functionalized PEG layers on surfaces, achieving the bio-specific adsorption of a target protein through an appropriate ligand tethered on PEG layers without non-specific adsorption of other proteins. These properties of polymeric micelles formed through the multimolecular assembly of block copolymers is highly useful as novel core-shell typed colloidal carriers for drug and gene targeting.

Surface organization of block copolymer micelles with cross-linking core was also highlighted here. Since the thin hydrogel layer made by alternate coating of micelles and PAlAm exhibited nonfouling properties and worked as the reservoir for hydrophobic reagents, these surfaces can be used in diverse fields of medicine and biology to construct high-performance medical devices and drug delivery systems.

Furthermore, by controlling metal and semiconductor structure precisely through the concept to construct functionalized PEG layers, one can modify the nanostructures to better suit their integration with biological systems; for example, modifying their surface layer for enhanced aqueous solubility, biocompatibility, and more importantly biorecognition. The use of exquisite recognition properties of biomolecules in organizing non-biological inorganic objects into functional materials led to new applications including ultrasensitive bioassays and mul- ticolor fluorescent labels for high-throughput detection and imaging.

\section{Acknowledgements}

The authors gratefully acknowledge Professors Y. Sakurai and T. Okano, Tokyo Women's Medical University, and Professor M. Kato, Science University of Tokyo for their help and stimulating discussions. The authors would like to acknowledge Dr K. Emoto and Mr M. Iijima for carrying out a part of this study. This study was partly supported by both CREST and The Research Fund for the Patentization(RFP) of JST (Japan Science and Technology Corporation).

\section{References}

[1] M. Moffitt, K. Khougaz, A. Eisenberg, Micellization of ionic block copolymers, Acc. Chem. Res. 29 (1996) 95-102.

[2] P. Munk, K. Prochazka, Z. Tuzar, S.E. Webber, Exploiting polymer micelle technology, CHEMTECH 28 (1998) 20-28.

[3] Z. Tuzar, P. Kratochvil, Micelles of block and graft copolymers in solutions, Surf. Colloid Sci. 15 (1993) 1-83.

[4] C. Allen, D. Maysinger, A. Eisenberg, Nano-engineering block copolymer aggregates for drug delivery, Colloids Surf. 16 (1999) 3-27.

[5] K. Kataoka, A. Harada, Y. Nagasaki, Block copolymer micelles for drug delivery: design, characterization and biological significance, Adv. Drug Deliv. Rev. 47 (2001) 113-131.

[6] S. Cammas-Marion, T. Okano, K. Kataoka, Functional and site-specific macromolecular micelles as high potential drug carriers, Colloids Surf. B 16 (1999) 207-215.

[7] E. Yu Kramarenko, I.I. Potemkin, A.R. Khokhlov, R.G. Winkler, P. Reineker, Surface micellar nanopattern formation of adsorbed diblock copolymer system, Macromolecules 32 (1999) 3495-3501.

[8] M. Antonietti, C. Göltner, Superstructures of functional colloids: chemistry on the nanometer scale, Angew. Chem. Int. Ed. Engl. 36 (1997) 910-928.

[9] K. Kataoka, G.S. Kwon, M. Yokoyama, T. Okano, Y. Sakurai, Block copolymer micelles as vehicles for drug delivery, J. Controlled Release 24 (1993) 119-132.

[10] K. Kataoka, Design of nanoscopic vehicles for drug targeting based on micellization of amphiphilic block copolymers, J. Macromol. Sci. Pure Apl. Chem. A31 (1994) 1759-1769.

[11] M. Yokoyama, T. Okano, Y. Sakurai, H. Ekimoto, C. Shibazaki, K. Kataoka, Toxicity and antitumor activity against solid tumors of micelle-forming polymeric anticancer 
drug and its extremely long circulation in blood, Cancer Res. 51 (1991) 3229-3236.

[12] M. Yokoyama, M. Mitauchi, N. Yamada, T. Okano, Y. Sakurai, K. Kataoka, S. Lnoue, Polymer micelles as novel drug carrier: adriamycin-conjugated poly(ethylene glycol)poly(aspartic acid) block copolymer, J. Controlled Release 11 (1990) 269-278.

[13] M.T. Peracchia, C. Vauthier, F. Puisieux, P. Couvreur, Development of sterically stabilized poly(isobutyl 2cyanoacrylate) nanoparticles by chemical coupling of poly(ethylene glycol), J. Biomed. Mater. Res. 34 (1997) 317326.

[14] K. Bergström, E. Österberg, K. Holmberg, A.S. Hoffman, T.P. Schuman, A. Kozlowski, J.H. Harris, Effects of branching and molecular weight of surface-bound poly(ethylene glycol) on protein rejection, J. Biomater. Sci. Polym. Edn. 6 (1994) 123-132.

[15] R. Gref, Y. Minamitake, M.T. Peracchia, V. Torchilin, V. Trubetskoy, R. Langer, Biodegradable long-circulating polymeric nanosphere, Science 28 (1994) 1600-1603.

[16] M.T. Peracchia, C. Vauthier, D. Desmaele, A. Gulik, J.C. Dedieu, M. Demoy, J. Angelo, P. Couvreur, Pegylated nanoparticles from a novel methoxypolyethylene glycol cyanoacrylate-hexadecyl cyanoacrylate amphiphilic copolymer, Pharm. Res. 15 (1998) 550-556.

[17] K. Holmberg, K. Bergstrom, C. Brink, E. Österberg, F. Tiberg, J.M. Harris, Effects on protein adsorption, bacterial adhesion and contact angle of grafting PEG chains to polystyrene, J. Adhesive Sci. Technol. 7 (1993) 503-517.

[18] L.K. Ista, H. Fan, O. Baca, G.P. Lopez, Attachment of bacteria to model surfaces: oligo(ethylene glycol) surfaces inhibit bacterial attachment, FEMS Microbiol. Lett. 142 (1996) 59-63.

[19] C.R. Deible, E.J. Beckman, A.J. Russell, W.R. Wagner, Creating molecular barriers to acute platelet deposition on damaged arteries with reactive polyethylene glycol, J. Biomed. Mater. Res. 41 (1998) 251-256.

[20] S. Jo, K. Park, Surface modification using silanated poly(ethylene glycol)s, Biomaterials 21 (2000) 605-616.

[21] H. Otsuka, Y. Nagasaki, K. Kataoka, Novel approaches for the construction of functionalized poly(ethylene glycol) (PEG) layer on surfaces using heterobifunctional PEG/polylactide(PLA) block copolymers and their micelles, in polymers from renewable resources: biopolyesters and biocatalysis, in: R. Gross, C. Scholz (Eds.), ACS Symposium Series 764, American Chemical Society, Washington, DC, 2000, pp. 311-327.

[22] H. Otsuka, Y. Nagasaki, K. Kataoka, Dynamic wettability study on the functionalized PEGylated layer on polylactide surface constructed by the coating of aldehyde-ended poly(ethylene glycol) (PEG)/polylactide (PLA) block copolymer, Sci. Technol. Adv. Mater. 1 (2000) 21-29.

[23] H. Otsuka, Y. Nagasaki, K. Kataoka, Surface characterization of functionalized polylactide through the coating with heterobifunctional poly(ethylene glycol)/polylactide block copolymers, Biomacromolecules 1 (2000) 39-48.

[24] H. Otsuka, Y. Nagasaki, K. Kataoka, Self-assembly of poly(ethylene glycol)-based block copolymers for biomedical applications, Curr. Opin. Colloid Interf. Sci. 6 (2001) 3-10.

[25] A.V. Kabanov, V.P. Chekhonin, V. Yu, V. Alakhov, E.V. Batrakova, A.S. Lebedev, N.S. Melik-Nubarov, S.A. Arzhakov, G.V. Morzov, E.S. Severn, V.A. Kabanov, The neuroleptic activity of haloperidol increases after its solubilization in surfactant miclles, FEBS Lett. 258 (1989) $343-$ 345.

[26] G.S. Kwon, M. Naito, M. Yokoyama, T. Okano, Y. Sakurai, K. Kataoka, Micelles based on AB block copolymers of poly(ethylene oxide) and poly( $\beta$-benzyl L-aspartate), Langmuir 9 (1993) 945-949.

[27] D. Bazile, C. Prud'homme, M.-T. Bassoullet, M. Marland, G. Spenlehauer, M. Veillard, Me. Stealth, PEG-PLA nanoparticles avoid uptake by the mononuclear phagocytes system, J. Pharm. Sci. 84 (1995) 493-498.

[28] S.A. Hagan, A.G.A. Coombes, M.C. Garnett, S.E. Dunn, M.C. Davis, L. Illum, S.S. Davis, S.E. Harding, S. Purkiss, P.R. Gellert, Polylactide-poly(ethylene glycol) copolymers as drug delivery systems. 1 . Characterization of water dispersible micelle-forming systems, Langmuir 12 (1996) 2153 2161.

[29] X. Zhang, J.K. Jackson, H.M. Burt, Development of amphiphilic block copolymers as micellar carriers of taxol, Int. J. Pharm. 132 (1996) 195-206.

[30] K. Yasugi, Y. Nagasaki, M. Kato, K. Kataoka, Preparation and characterization of polymer micelle from poly(ethylene glycol)-poly(D,L-lactide) block copolymer as potential drug carrier, J. Controlled Release 62 (1999) 89-100.

[31] A. Hadada, K. Kataoka, Formation of polyion complex micelles in aqueous milieu from a pair of oppositely-charged block copolymers with poly(ethylene glycol) segments, Macromolecules 28 (1995) 5294-5299.

[32] K. Kataoka, H. Togawa, A. Harada, K. Yasugi, T. Matsumoto, S. Katayose, Spontaneous formation of polyion complex micelles with nallow distribution from antisense oligonucleotide and cationic block copolymer in physiological saline, Macromolecules 29 (1996) 8556-8557.

[33] T.K. Bronich, A.V. Kabanov, V.A. Kabanov, K. Yu, A. Eisenberg, Soluble complex from poly(ethylene oxide)-block-polymethecrylate anions and $N$-alkylpyridinium cations, Macromolecules 33 (1997) 3519-3525.

[34] E.A. Lysenko, T.K. Bronich, A. Eisenberg, V.A. Kabanov, A.V. Kabanov, Block ionomer complexes from polystyreneblock-polyacrylate anions and $N$-cetylpyridinium cations, Macromolecules 31 (1998) 4511-4515.

[35] M. Yokoyama, T. Okano, Y. Sakurai, S. Suwa, K. Kataoka, Introduction of cisplatin into polymeric micelle, J. Controlled Release 39 (1996) 351-356.

[36] N. Nishiyama, M. Yokoyama, T. Aoyagi, T. Okano, Y. Sakurai, K. Katakoka, Preparation and characterization of self-assembled polymer-metal complex micelle from cisdichlorodiamine platinum (II) and poly(ethylene glycol)poly(a,b-aspartic acid) block coplymer in an aqueous medium, Langmuir 15 (1999) 377-383.

[37] K. Kataoka, A. Ishihara, A. Harada, H. Miyazaki, Effect of secondary structure of poly(L-lysine) segments on the micel- 
lization of poly(ethylene glycol)-poly(L-lysine) block copolymer partially substituted with hydrocynnamoyl-group at the $N$-position in aqueous milieu, Macromolecules 31 (1998) 6071-6076.

[38] H. Weller, Colloidal semiconductor Q-particle-chemistry in the transition region between solid-state and molecules, Angew. Chem., Int. Ed. Engl. 32 (1993) 41-53.

[39] R.F. Khairutdinov, Physical chemistry of nanocrystalline semiconductors, Colloid J. 59 (1997) 535-548.

[40] H.H. Huang, F.Q. Yan, J.M. Kek, C.H. Chew, G.Q. Xu, W. Ji, P.S. Oh, S.H. Tang, Synthesis, characterization, and nonlinear optical properties of copper nanoparticles, Langmuir 13 (1997) 172-175.

[41] A.L. Rogach, A. Eychmuller, A. Kornowski, H. Weller, Thiol-stabilized CdSe and CdTe nanocrystals in the size quantization regime: Synthesis, optical and structural properties, Macromol. Symp. 136 (1998) 87-89.

[42] J.H. Fendler, Y. Tian, in: J.H. Fendler (Ed.), Nanoparticles and Nanostructured Film, Wiley, Weinheim, 1998.

[43] E.S. Smotkin, L. Chongmok, A.J. Bard, A. Campion, M.A. Fox, T.E. Mallouk, S.E. Webber, Size quantization effects in cadmium-sulfide layers formed by a Langmuir-Blodgett technique, Chem. Phys. Lett. 152 (1988) 265-268.

[44] L.S. Li, L.H. Qu, R. Lu, X.G. Peng, Y.Y. Zhao, T.J. Li, Preparation and structure of quantum-sized cadmium sulfide grown in amphiphilic oligomer Langmuir-Blodgett films, Thin Solid Films 329 (1998) 408-411.

[45] P. Lianos, J.K. Thomas, Cadmium-sulfide of small dimensions produced in inverted micelles, Chem. Phys. Lett. 125 (1986) 299-302.

[46] M.P. Pileni, L. Motte, F. Billoudet, C. Petit, Synthesized 'in situ' in reverse micelles of silver-sulfide semiconductors, Surf. Rev. Lett. 3 (1996) 1215-1218.

[47] H.-C. Youn, S. Baral, J.H. Fendler, Dihexadecyl phosphate vesicle-stabilized and insitu generated mixed $\mathrm{CdS}$ and $\mathrm{ZnS}$ semiconductor particles-preparation and utilization for photosensitized charge separation and hydrogen generation, J. Phys. Chem. 92 (1988) 6320-6327.

[48] M. Moffitt, A. Eisenberg, Size control of nanoparticles in semiconductor-polymer composites. 1. Control via multiplet aggregation numbers in styrene-based random ionomers, Chem. Mater. 7 (1995) 1178-1184.

[49] M. Moffitt, L. McMahon, V. Pessel, A. Eisenberg, Size control of nanoparticles in semiconductor-polymer composites. 2. Control via sizes of spherical ionic microdomains in styrene-based diblock ionomers, Chem. Mater. 7 (1995) 1185-1192.

[50] M. Antonietti, E. Wenz, L. Bronstein, M. Seregina, Synthesis and characterization of noble metal colloids in block copolymer micelles, Adv. Mater. 7 (1995) 1000-1005.

[51] Y. Matsumura, H. Maeda, A new concept for macromolecular therapeutics in cancer chemotherapy: mechanism of tumoritropic accumulation of proteins and the antitumor agent smancs, Cancer Res. 46 (1986) 6387-6392.

[52] Y. Nagasaki, T. Kutsuna, M. Iijima, M. Kato, K. Kataoka, Formyl-ended heterobifunctional poly(ethylene oxide): Synthesis of poly(ethylene oxide) with a formyl group at one end and a hydroxyl group at the other end, Bioconjug. Chem. 6 (1995) 231-233.

[53] Y. Nagasaki, M. Iijima, M. Kato, K. Kataoka, Primary amino-terminal heterobifunctional poly(ethylene oxide). Facile synthesis of poly(ethylene oxide) with a primary amino group at one end and a hydroxyl group at the other end, Bioconjug. Chem. 6 (1995) 702-704.

[54] Y. Nagasaki, R. Ogawa, S. Yamamoto, M. Kato, K. Kataoka, Synthesis of heterotelechelic poly(ethylene glycol) macromonomers. Preparation of poly(ethylene glycol) possessing a methacryloyl group at one end and a formyl group at the other end, Macromolecules 30 (1997) 6489-6493.

[55] T. Nakamura, Y. Nagasaki, K. Kataoka, Synthesis of heterobifunctional poly(ethylene glycol) with a reducing monosaccharide residue at one end, Bioconjug. Chem. 9 (1998) 300-303.

[56] Y. Akiyama, H. Otsuka, Y. Nagasaki, K. Kataoka, Selective synthesis of heterobifunctional poly(ethylene glycol) derivatives containing both mercapto and acetal terminals, Bioconjug. Chem. 11 (2000) 947-950.

[57] Y. Nagasaki, T. Okada, C. Scholz, M. Iijima, M. Kato, K. Kataoka, The reactive polymeric micelle based on an aldehyde-ended poly(ethylene glycol)/poly(lactide) block copolymer, Macromolecules 31 (1998) 1473-1479.

[58] K. Yasugi, T. Nakamura, Y. Nagasaki, M. Kato, K. Kataoka, Sugar-installed polymer micelles: Synthesis and micellization of poly(ethylene glycol)-poly(D,L-lactide) block copolymers having sugar groups at PEG chain end, Macromolecules 32 (1999) 8024-8032.

[59] Y. Yamamoto, Y. Nagasaki, M. Kato, K. Kataoka, Surface charge modulation of poly(ethylene glycol)-poly(D,L-lactide) block copolymer micelles: conjugation of charged peptides, Colloids Surf. B: Biointerf. 16 (1999) 135-146.

[60] M.A. Woflert, E.H. Schacht, V. Toncheva, K. Ulbrich, O. Nazarova, L.W. Seymour, Characterization of vector for gene therapy formed by self-assembly of DNA with synthetic block co-polymers, Hum. Gene Ther. 7 (1996) 2123-2133.

[61] S. Katayose, K. Kataoka, Water soluble polyion complex associates of DNA and poly(ethylene glycol)-poly(L-lysine) block copolymer, Bioconjug. Chem. 8 (1997) 702-707.

[62] S. Katayose, K. Kataoka, Remarkable increase in nuclease resistance of plasmid DNA through supramolecular assembly with poly(ethylene glycol)-poly(L-lysine) block copolymer, J. Pharm. Sci. 87 (1998) 160-163.

[63] Y. Akiyama, A. Harada, Y. Nagasaki, K. Kataoka, Synthesis of poly(ethylene glycol)-block-poly(ethyleneimine) possessing an acetal group at the PEG end, Macromolecules 33 (2000) 5841-5845.

[64] K. Kataoka, A. Harada, D. Wakebayashi, Y. Nagasaki, Polyion complex micelles with reactive aldehyde groups on their surface from plasmid DNA and end-functionalized charged block copolymers, Macromolecules 32 (1999) 6892-6894.

[65] Y. Kakizawa, K. Kataoka, Block copolymer micelles for delivery of gene and related compounds, Adv. Drug Deliv. Rev. 54 (2002) 203-222.

[66] J.P.S. Farinha, J.M.R. d'Oliveira, J.M. Martinoho, R. Xu, 
M.A. Winnik, Structure in tethered chains: polymeric micelles and chains anchored on polystyrene latex spheres, Langmuir 14 (1998) 2291-2296.

[67] H.D. Bijsterbosch, M.A. Cohen Stuart, G.J. Fleer, Adsorption kinetics of diblock copolymers from a micellar solution on silica and titania, Macromolecules 31 (1998) 9281-9294.

[68] A. Jonner, J.F. Joanny, Block copolymer adsorption in a selective solvent: a kinetic study, Macromolecules 26 (1990) 5299-5311.

[69] M. Iijima, Y. Nagasaki, T. Okada, M. Kato, K. Kataoka, Core-polymerized reactive micelles from heterotelechelic amphiphilic block copolymers, Macromolecules 32 (1999) 1140-1146

[70] K. Emoto, Y. Nagasaki, K. Kataoka, Coating of surfaces with stabilized reactive micelles from poly(ethylene glycol)-poly(D,L-lactic acid) block copolymer, Langmuir 15 (1999) 5212-5218.

[71] K. Emoto, Y. Nagasaki, K. Kataoka, A core-shell structured hydrogel thin layer on surfaces by lamination of a poly(ethylene glycol)- $b$-(D,L-lactide) micelle and polyallylamine, Langmuir 16 (2000) 5738-5742.

[72] K. Emoto, M. Iijima, Y. Nagasaki, K. Kataoka, Functionality of polymeric micelle hydrogels with organized three-dimensional architecture on surfaces, J. Am. Chem. Soc. 122 (2000) 2653-2654.

[73] S.J. Sofia, V. Premnath, E.W. Merrill, Poly(ethylene glycol) grafted to silicon surfaces: grafting density and protein adsorption, Macromolecules 31 (1998) 5059-5070.

[74] S.T. Lopina, G. Wu, E.W. Merrill, L. Griffith-Cima, Hepatocyte culture on carbohydrate-modified star polyethylene oxide hydrogels, Biomaterials 17 (1996) 559-569.

[75] P.K. Smith, R.I. Krohn, G.T. Hermanson, A.K. Mallia, F.H. Gartner, M.D. Provenzano, F.K. Fujimoto, N.M. Goeke, B.J. Olson, D.C. Klenk, Measurement of protein using bicinchoninic acid, Anal. Biochem. 150 (1985) 76-85.

[76] G.S. Kwon, S. Suwa, M. Yokoyama, T. Okano, Y. Sakurai, K. Kataoka, enhanced tumor accumulation and prolonged circulation times of micelle-forming poly(ethylene oxideaspartate) block copolymer-adriamycin conjugates, J. Controlled Release 29 (1994) 17-23.

[77] A. Henglein, Small-particle research: physicochemical properties of extremely small colloidal metal and semiconductor particles, Chem. Rev. 89 (1989) 1861-1873.

[78] G. Schmid, Large clusters and colloids: metals in the embryonic state, Chem. Rev. 92 (1992) 1709-1727.

[79] A.P. Alvisatos, Semiconductor clusters, nanocrystals, and quantum dots, Science 271 (1996) 933-937.

[80] M. Nirmal, L.E. Brus, Luminescence photophysics in semiconductor nanocrystals, Acc. Chem. Res. 32 (1999) $404-$ 414.

[81] C.A. Mirkin, T.A. Taton, Semiconductors meet biology, Nature 405 (2000) 626-627.

[82] C.M. Niemeyer, Nanoparticles, proteins, and nucleic acids: biotechnology meets materials science, Angew. Chem., Int. Ed. Engl. 40 (2001) 4128-4158.

[83] H. Otsuka, Y. Akiyama, Y. Nagasaki, K. Kataoka, Quantitative and reversible lectin-induced association of gold nanoparticles modified with $\alpha$-lactosyl- $\omega$-mercapto-poly(ethylene glycol), J. Am. Chem. Soc. 123 (2001) 82268230.

[84] J.M. de la Fuente, A.G. Barrientos, T.C. Rojas, J. Rojo, J. Cañada, A. Fernández, S. Penadés, Gold glyconanoparticles as water-soluble polyvalent models to study carbohydrate interactions, Angew. Chem., Int. Ed. Engl. 40 (2001) 22582261.

[85] T.C. Rojas, J.M. de la Fuente, A.G. Barrientos, S. Penadés, L. Ponsonnet, A. Fernández, Gold glyconanoparticles as building blocks for nanomaterials design, Adv. Mater. 14 (2002) 585-588.

[86] C.-C. Lin, Y.-C. Yen, C.-Y. Yang, C.-L. Chen, G.-F. Chen, C.-C. Chen, Y.-C. Wu, Selective binding of mannose-encapsulated gold nanoparticles to type 1 pill in Escherichia coli, J. Am. Chem. Soc. 124 (2002) 3508-3509.

[87] S.R. Whaley, D.S. English, E.L. Hu, P.F. Barbara, A.M. Belcher, Selection of peptides with semiconductor binding specificity for directed nanocrystal assembly, Nature 405 (2000) 665-668.

[88] M. Bruchez Jr., M. Moronne, P. Gin, S. Weiss, A.P. Alvisatos, Semiconductor nanocrystals as fluorescent biological labels, Science 281 (1998) 2013-2015.

[89] W.C.W. Chan, S.M. Nie, Quantum dot bioconjugates for ultrasensitive nonisotopic detection, Science 281 (1998) 2016-2018.

[90] H. Mattoussi, J.M. Mauro, E.R. Goldman, G.P. Anderson, V.C. Sunder, F.V. Mikulec, M.G. Bawendi, Self-assembly of CdSe-ZnS quantum dots bioconjugates using an engineered recombinant protein, J. Am. Chem. Soc. 122 (2000) 12142 12150 .

[91] G.P. Mitchell, C.A. Mirkin, R.L. Letsinger, Programmed assembly of DNA functionalized quantum dots, J. Am. Chem. Soc. 121 (1999) 8122-8123.

[92] Y.W. Cao, R. Jin, C.A. Mirkin, DNA-modified core-shell Ag/Au nanoparticles, J. Am. Chem. Soc. 123 (2001) 79617962.

[93] S.-J. Park, A.A. Lazarides, C.A. Mirkin, R.L. Letsinger, Directed assembly of periodic materials from protein and oligonucleotide-modified nanoparticles building blocks, Angew. Chem., Int. Ed. Engl. 40 (2001) 2909-2912.

[94] C.A. Mirkin, R.L. Letsinger, R.C. Mucic, J.J. Storhoff, A DNA-based method for rationally assembling nanoparticles into macroscopic materials, Nature 382 (1996) 607-609.

[95] A.P. Alvisatos, K.P. Johnsson, X. Peng, T.E. Wilson, C.J. Loweth, M.P. Bruchez Jr., P.G. Schultz, Organization of nanocrystal molecules using DNA, Nature 382 (1996) 609_ 611.

[96] R. Elghanian, J.J. Storhoff, R.C. Mucic, R.L. Letsinger, C.A. Mirkin, Selective colorimetric detection of polynucleotides based on the distance-dependent optical properties of gold nanoparticles, Science 277 (1997) 1078-1081.

[97] B. Dubertret, M. Calame, A.J. Libchaber, Single-mismatch detection using gold-quenched fluorescent oligonucleotides, Nat. Biotechnol. 19 (2001) 365-370.

[98] R.A. Reynolds, C.A. Mirkin, R.L. Letsinger, Homogeneous, nanoparticle-based quantitative colorimetric detection of oligonucleotides, J. Am. Chem. Soc. 122 (2000) 3795-3796. 
[99] M. Hayat (Ed.), Colloidal Gold: Principles, Methods and Applications, Academic Press, San Diego, 1989.

[100] G. Schmid:, Clusters and Colloids, VCH, Weinheim, 1994.

[101] U. Kreibig:, Optical Properties of Metal Clusters, Springer, New York, 1995.

[102] A.P. Alvisatos, Semiconductor clusters, nanocrystals, and quantum dots, Science 271 (1996) 933-937.

[103] D.L. Feldheim, C.D. Keating, Self-assembly of single electron transistors and related devices, Chem. Soc. Rev. 27 (1998) 1-12.

[104] A.N. Shipway, E. Katz, I. Willner, Nanoparticle arrays on surfaces for electronic, optical, and sensor applications, ChemPhysChem 1 (2000) 18-52.

[105] T. Sato, R. Ruch, Stabilization of Colloidal Dispersions by Polymer Adsorption; Surfactant Science Series, No. 9, Marcel Dekker, New York, 1980.

[106] R.G. Pearson, Hard and soft acids and bases, J. Am. Chem. Soc. 85 (1963) 3533-3539.

[107] L.-H. Lee (Ed.), Fundamentals of Adhesion, Plenum Press, New York, 1991.

[108] L. Bronstein, M. Sedlak, J. Hartmann, M. Breulmann, H. Cölfen, M. Antonietti, Polym. Prepr. (Am. Chem. Soc., Div. Polym.) 76 (1997) 54.

[109] L.M. Bronstein, S.N. Sidorov, P.M. Valetsky, J. Hartmann, H. Cölfen, M. Antonietti, Induced micellization by interaction of poly(2-vinylpyridine)-block-poly(ethylene oxide) with metal compounds. Micelle characteristics and metal nanoparticle formation, Langmuir 15 (1999) 6256-6262.

[110] S.N. Sidorov, L.M. Bronstein, P.M. Valetsky, J. Hartmann, H. Cölfen, H. Schnablegger, M. Antonietti, Stabilization of metal nanoparticles in aqueous medium by polyethyleneoxide-polyethyleneimine block copolymers, J. Colloid Interf. Sci. 212 (1999) 197-211.

[111] W.P. Wuelfing, S.M. Gross, D.T. Miles, R.W. Murray, Nanometer gold clusters protected by surface-bound monolayers of thiolated poly(ethylene glycol) polymer electrolyte, J. Am. Chem. Soc. 120 (1998) 12696-12697.

[112] L. Quaroni, G. Chumanov, Preparation of polymer-coated functionalized silver nanoparticles, J. Am. Chem. Soc. 121 (1999) 10642-10643.

[113] P.A. Buining, B.M. Humbel, A.P. Philipse, A.J. Verkleij, Preparation of functional silane-stabilized gold colloids in the (sub)nanometer size range, Langmuir 13 (1997) 39213926.

[114] H. Otsuka, Y. Akiyama, Y. Nagasaki, K. Kataoka, Quantitative and reversible lectin-induced association of gold nanoparticles modified with $\alpha$-lactosl- $\omega$-mercapto-poly(ethylene glycol), J. Am. Chem. Soc 123 (2001) 82268230 .

[115] I.J. Goldstein, R.D. Poretz, 2. Isolation, physicochemical characterization, and carbohyderate-binding specificity of lectins, in: I.E. Liener, N. Sharon, I.J. Goldstein (Eds.), The Lectins. Properties, Functions, and Applications in Biology and Medicine, Academic Press, Orlando, FL, 1986, pp. 35-244.

[116] E.C. Sweeney, A.G. Tonevitsky, D.E. Temiakov, I.I. Agapov, S. Saward, R.A. Palmer, Preliminary crystallographic characterization of ricin agglutinin, Proteins 28 (1997) 586-589.

[117] G. Mie, Ann. Phys. 25 (1908) 377.

[118] L.A. Lyon, M.D. Musick, M.J. Natan, Colloidal Au-enhanced surface plasmon resonance immunosencing, Anal. Chem. 70 (1998) 5177-5183.

[119] L. He, M.D. Musick, S.R. Nicewarner, F.G. Salinas, S.J. Benkovic, M.J. Natan, C.D. Keating, Colloidal Au-enhanced surface plasmon resonance for ultrasensitive detection of DNA hybridization, J. Am. Chem. Soc. 122 (2000) 9071-9077.

[120] (a) For reviews on surface plasmon resonance measurement, see: (a) J.M. Brockman, B.P. Nelson, R.M. Corn, Surface plasmon resonance imaging measurement of ultrathin organic films, Annu. Rev. Phys. Chem. 51 (2000) 41-63;

(b) C. Williams, Biotechnology match making: screening orphan ligands and receptors, Curr. Opin. Biotechnol. 11 (2000) 42-46;

(c) R.L. Rich, D.G. Myszka, Advances in surface plasmon resonance biosencor analysis, Curr. Opin. Biotechnol. 11 (2000) 54-61.

[121] M. Dahan, T. Laurence, F. Pinaud, D.S. Chemla, A.P. Alivisatos, M. Sauer, S. Weiss, Time-gated biological imaging by use of colloidal quantum dots, Opt. Lett. 26 (2001) 825-827.

[122] X.G. Peng, J. Wickham, A.P. Alivisatos, Kinetics of II-VI and III-V colloidal semiconductor nanocrystal growth: 'focusing' of size distribution, J. Am. Chem. Soc. 120 (1998) 5343-5344.

[123] J.K. Lorenz, A.B. Ellis, Surfactant-semiconductor interfaces: perturbation of the photoluminescence of bulk cadmium selenide by adsorption of tri- $n$-octylphosphine oxide as a probe of solution aggregation with relevance to nanocrystal stabilization, J. Am. Chem. Soc. 120 (1998) 10970-10975.

[124] J. Huang, K. Sooklal, C.J. Murphy, Polyamine-quantum dot nanocomposites: linear versus starburst stabilizer architecture, Chem. Mater. 11 (1999) 3595-3601.

[125] I. Sondi, O. Siiman, S. Koester, E. Matijevic, Preparation of amidodextran-CdS nanoparticle complexes and biologically active antibody-amidodextran-CdS nanoparticle conjugates, Langmuir 16 (2000) 3107-3118. 